\title{
Cultura, consumo e estereótipos: significações de estudantes do curso de educação artística
}

\begin{abstract}
RESUMO
O presente estudo faz parte de uma investigação maior que discute a influência dos estereótipos veiculados pela televisão na formação de acadêmicas do curso de Educação Artística: Habilitação em Artes Plásticas - LP da Universidade de Passo Fundo. Os objetivos visam investigar a percepção das participantes a respeito dos modelos estéticos humanos construídos/reproduzidos pela mídia televisiva.
\end{abstract}

\section{PALAVRAS-CHAVE}

- cultura

- consumo

- educação

\section{ABSTRACT}

This study is part of a bigger research that discusses the influence of stereotypes presented by television in the formation of Artistic Education: Fine Arts students, at Universidade de Passo Fundo. The objectives look for research the participants' perception about aesthetic human models construed / reproduced by mass media.

\section{KEY WORDS}

- culture

- consume

- education

\author{
Graciela Ormezzano, Cilene Maria Potrich, \\ Bibiana Friderichs, Lílian Cordeiro Araldi \\ UPF
}

E sta investigação faz parte de uma investigação maior que discute a influência dos estereótipos veiculados pela televisão na formação de acadêmicas do curso de Educação Artística: Habilitação em Artes Plásticas da Universidade de Passo Fundo. Dessa pergunta inicial derivam metas a serem alcançadas, que visam investigar a percepção das participantes a respeito dos modelos estéticos humanos construídos/reproduzidos pela mídia televisiva e identificar os estereótipos humanos apresentados na televisão, segundo o olhar das entrevistadas. O termo "estereótipo" pode ser definido como algo reproduzido e, por conseguinte, onde não fertiliza a criatividade ou a inovação, dificultando sobremaneira outras formas de pensar ou observar a realidade.

Este estudo justifica-se pela possibilidade de discutir a influência dos estereótipos apresentados pela televisão na formação de educadores imersos numa cultura visual e por ser um espaço fundamental em que gerações de jovens se predispõem a criticar ou ao qual se conformam cotidianamente para fazer a leitura do mundo que os cerca.

O campo de ação desta pesquisa foi a Faculdade de Artes e Comunicação da UPF, na qual entrevistamos alunas do curso em questão, sendo um total de doze mulheres adultas jovens com idades entre $18 \mathrm{e}$ 27 anos, brancas, de classe média ou média baixa, o que consideramos adequado, tratando-se de uma pesquisa qualitativa.

Com vistas a compreender as informações coletadas, utilizamos o método fenomenológico, proposto por Giorgi e Comiotto (ORMEZZANO, TORRES, 2003), que possibilitou a emergências das essências fenomenológicas, das quais focaremos somente duas, uma vez que ambas estão intimamente ligadas a ação dos média no cenário social:

1. Relações subjetivas e intersubjetivas diante da $\mathrm{TV}$, composta pelas pessoas idealizadas e os motivos que levam à identificação; o âmbito das relações familiares diante da televisão e as questões educacionais e/ou educativas em programas vistos ou mencionados pelas entrevistadas;

2. Indústria cultural e comunicação de massa, abordando as relações ambientais entre sociedade, cultura e consumo, assim como as percepções sobre a influência da TV no telespectador e o fenômeno de comunicação massiva. 


\section{Relações subjetivas e intersubjetivas diante da televisão}

Muitos embates acerca da influência da televisão apontam para a ambivalência afetiva desse meio, pois ela é, ao mesmo tempo, amada e odiada, desejada e desprezada. Embora tenhamos uma certa consciência das suas implicações negativas, nenhum lar de nosso tempo vive sem tê-la. É necessário, então, tentar compreender sua função explícita e suas conseqüências implícitas na subjetividade das pessoas.

Com as crianças, uma relação de dependência com a televisão é iniciada desde muito cedo. É possível dizer que a televisão se tornou um substituto da babá e até mesmo da mãe. Se a TV vem tomando o lugar dessa figura tão importante, podemos inferir que as conseqüências dessa dependência são extremamente relevantes.

$\mathrm{Na}$ fase adulta, a televisão apresenta-se como um fetiche, um objeto de desejo, tanto pelo que expressa, quanto pelo que mostra. A TV é objeto medial entre a realidade e a vida das pessoas. $\mathrm{O}$ que ela mostra é associado à realidade, àquilo que acontece no mundo. Como diz a entrevistada $N$ : "[...] nas novelas é toda uma imitação, um teatro, mas, mesmo assim, eu fico admirando aquela vivência, aquela falsidade que eles passam e parece tão real pra gente."

Segundo Ferrés, a televisão é o totem das pessoas da nossa sociedade, pois é objeto de veneração e reverência e símbolo de identificação, tanto individual quanto coletivo. "Como totem, a televisão concentra as expectativas e temores das tribos modernas. A ela sacrificam o seu tempo. Ela dá sentido (?) à realidade. Decide o que é e o que não é importante. E produz o prazer de saber-se e sentir-se integrado dentro de uma coletividade" (1996, p.7). A televisão é, portanto, a nova religião pós-moderna. Fazendo uma análise pertinente dos processos cognitivos diante da televisão, Ferrés traça um paralelo acerca do modo como ocorre a comunicação na televisão e na leitura. A TV, baseada na visão e, portanto, nas imagens é dinâmica, ao passo que o universo da leitura é estático. A leitura oportuniza o discernimento, mas a TV favorece as gratificações sensorial, visual e auditiva. Ainda o autor define a linguagem verbal dizendo que " [...] é uma abstração da experiência, enquanto que a imagem é uma representação concreta da experiência. Se o livro favorece o conhecer, a imagem favorece o reconhecer. Se o texto oral é especialmente indicado para explicar, o audiovisual é indicado para associar" (1996, p. 21). Portanto, ver televisão é uma operação automática, sem muita reflexão; já na leitura, são necessárias complexas operações analíticas e racionais. A informação icônica infiltra-se sem as mediações dos processos da razão, o que favorece o envolvimento apenas em nível emocional com os símbolos televisivos. Na leitura o sujeito controla a experiência; na televisão, é o meio o controlador.
Desse modo, as respostas produzidas pela decodificação de imagens são muito mais emotivas do que racionais e toda a linguagem televisiva é pensada para provocar isso. A câmera mostra os objetos com uma aproximação afetiva, verdadeira sedução, como que proporcionando ao espectador a possibilidade de tocá-los com os olhos. O discurso negativo que subjaz principalmente em relação à propaganda desaparece diante do tratamento mágico dado à imagem. Esse tratamento pode ser dado também às pessoas ou às personagens, um dos motivos prováveis que leva a que as entrevistadas se identifiquem com alguém ou projetem em alguém sentimentos ou desejos.

As pessoas mais significativas para as entrevistadas foram cantores, jornalistas, apresentadores de diversos tipos de programas e até membros do governo, pessoas que foram escolhidas pelas participantes ao utilizarem a lógica do coração. “A empatia do rosto é simpatia. [...] A participação na realidade do outro surge desde seu mesmo fundamento." (MÈLICH, 1994, p. 152-153). A intencionalidade educativa no cotidiano implica participação, conduzindo-nos à experiência estética. Na participação a pessoa ou personagem televisivos compartilha com o telespectador um terreno comum, um texto compartido e comprometido na reciprocidade. Os ídolos ou mitos não existiriam sem quem os admire e vice-versa.

A identificação e a projeção acontecem no viver cotidiano das pessoas. Evidentemente, são manifestas no espectador quando ele integra-se emocionalmente com o espetáculo televisivo. O processo de identificação ocorre quando o espectador assume o ponto de vista da pessoa ou da personagem, tomando-o para si como um reflexo de sua situação de vida. Já a projeção acontece quando o espectador projeta seus sentimentos sobre o sujeito ou personagem televisivo, amando aqueles que o outro ama, odiando da mesma forma que o outro odeia e assim por diante. Essas atitudes são próprias dos espetáculos de massa, onde a intenção é envolver emocionalmente o espectador. No caso da televisão, o aumento do prazer está associado à falta de riscos e compromissos que são assumidos diante dos fatos.

Esses processos de identificação e de transferência referem-se a níveis muitas vezes inconscientes do espectador. Além do inconsciente pessoal, é necessário considerar o inconsciente coletivo, justificando o aparecimento dos mitos, esses surgidos de uma necessidade coletiva das pessoas. "Em todos esses casos os processos projetivos são produzidos sobre a mitologia criada pela sociedade de massas em torno das pessoas investidas com atributos míticos de beleza, sedução, força ou poder" (FERRÉS, 1996, p. 38).

Anteriormente, as projeções davam-se com deuses e heróis, com seus poderes sobre-humanos. Hoje, os heróis pertencem à indústria cultural, são as es- 
trelas do cinema e das novelas, os ídolos do esporte e da música. Podemos projetar no ídolo da televisão não só nossos desejos, mas também, sobretudo, nossos medos, tristezas, incertezas e, principalmente, aquilo que não temos coragem de viver, ou não temos condições de fazer. K. relata: “Há um desenho animado em que o mal faz de tudo para que o bem se desmanche, na última hora, o bem consegue reverter a situação. Então, eu acho que isso não é bom para a criança assistir, porque mostra que o mal é fácil de fazer e o bem é mais difícil, embora vença na última hora." Nesses eventos, a televisão serve como um exorcismo ou como catarse. No caso das cenas de violência, como ocorria na tragédia grega, o personagem vivencia aquilo que não se pode fazer, levando o espectador a uma satisfação semelhante, porém enganatória da sua vivência. A catarse, então, como purificação das emoções perturbadoras ou hostis, é "uma descarga ou transferência da própria culpa" (FERRÉS, 1996, p.40).

A suspensão da incredulidade do espectador diante da televisão emerge numa situação semelhante à esquizofrenia, pois ele sabe, racionalmente, que o que se passa é fantasia, mas se envolve emocionalmente como se realidade fosse. Como exemplo, há os filmes de terror, nos quais, embora saibamos se tratar de ficção, reagimos com medo profundo.

Para que haja uma identificação ou projeção, é necessário que o programa fale ao espectador tanto em nível consciente como no inconsciente, principalmente de forma a saciar suas pulsões. Caso isso não ocorra, provavelmente o programa não terá os índices de audiência esperados. O contrário também é verdadeiro, pois, se a satisfação das pulsões for feita de forma explícita, o superego do espectador pode intervir, rejeitando-a como algo grosseiro ou agressivo.

Desse modo, a TV é um espelho tal como o mito de Narciso e as identificações se dão porque nos projetamos naqueles aos quais admiramos. Contudo, a televisão se propõe e utiliza técnicas apuradas para provocar isso, principalmente com objetivos comerciais, manipulando as opiniões e gerando identificações sobre as quais não se reflete. No caso desta pesquisa, é possível afirmar que as pessoas e/ou personagens com as quais as entrevistadas disseram se identificar, expressam essa projeção narcísea. $V$. declara: "A ministra do Meio Ambiente, do governo Lula, me marcou porque há proximidade. Nós duas temos garra, persistência, ligação com a terra e somos de famílias simples." E J, por exemplo, disse que se identifica com Sérgio Brito porque idealiza o seu conhecimento vasto, a busca pela cultura e as informações relativas à arte e que até sente um pouco de inveja diante da bagagem acumulada pelo apresentador.

Não é possível falar de identificação e projeção sem abordar os estereótipos, e a televisão é mestra em manipulá-los, do que provém sua imensa capa- cidade de penetração cultural. Vejamos o caso de $W$, que participa de grupos de ajuda voluntários a famílias carentes e admira Netinho porque, "sendo de uma comunidade pobre ele faz um trabalho na TV de auxílio a seu grupo originário." Segundo Gomes, "o estereótipo é uma espécie de simplificação modeladora de imagens, fazendo-as estas exprimirem uma solução segura, certamente identificável" (2002, p. 33). O estereótipo é utilizado porque promove uma identificação ou decodificação da mensagem mais rapidamente e sem esforço de reflexão; e, portanto, um dos recursos mais eficientes de manipulação. Se a TV influi de forma decisiva na maneira como entendemos e vemos a nossa realidade social e se a forma como mostra essa realidade é estereotipada, então resta nos questionarmos de que maneira estamos construindo a nossa visão de mundo, especialmente, em relação às crianças.

Ferrés (1996) aponta como mais significativos os estereótipos que se referem aos papéis sexuais, raciais, profissionais e sociais, o que pode provocar sérios problemas nas populações apresentadas de forma estereotipada, como os negros ou homossexuais, por exemplo. Com essas populações torna-se praticamente impossível a identificação, pois não são apresentados como personagens poderosos e bemsucedidos, gerando uma rejeição facilmente transportável para o viver diário das pessoas.

E falando em questões de cotidiano, precisamos tomar em conta as relações familiares diante da TV. Já que a televisão faz parte do convívio familiar, ocupando muitas vezes até o lugar do diálogo do casal ou da família, provoca uma sensação de angústia, de carência ou aborrecimento, quando há, por exemplo, falta de energia elétrica. Nesse sentido, a televisão, acompanha a tendência à industrialização e à atomização da família, garantindo o isolamento e a não-comunicação entre as pessoas. Assim, a autoridade dos pais sobre os filhos se esfuma em prol da difusão, produção e consumo da mercadoria e seu ideário (ALVES, 1995).

A televisão é muito exigente, ela precisa de uma atenção constante, o que leva algumas famílias a organizarem tempo e espaço em função da sua programação. As refeições, a hora de dormir, os objetos que vão ser consumidos, tudo é determinado pela televisão, como revela a fala de $N$ : "Eu acho que isso poda muito às vezes a gente de se comunicar, contar, desde o nosso dia-a-dia, que é tão importante pra gente e a gente vai deixando, parece que a TV, às vezes, é algo de mais precioso na casa, sendo que o que é mais precioso é a nossa vida [...]".

Um modo de entender isso pode ser encontrado na diversão - diversão enquanto necessidade de fuga da realidade -, na busca de uma vivência diferente depois de um dia de trabalho exaustivo. Diante da TV as famílias, ao final do dia, não querem discutir seus problemas, apenas se distrair com os programas que não exigem muito raciocínio, auxiliando-as 
a esquecerem os fatos que podem ter produzido o estresse cotidiano.

A criança tem hoje, diante da televisão, acesso não somente à diversão, mas a uma diversidade de informações e experiências indiretas, em detrimento das experiências vividas. Essas informações, que se dão excessivamente, vão aproximando-as do universo dos adultos, forçando-as a uma maturidade precoce, como aparece na fala da entrevistada $B$ : “[...] eles vão perdendo a sensibilidade, o momento criança deles, que eles deveriam ter, estão perdendo a oportunidade de viver essa fase."

É inegável que a televisão participa da construção da visão de mundo, sobretudo das crianças. Ela não pode, então, ser dissociada do meio em que se situa, como bem cultural produzido e consumido pela sociedade, cuja função declarada é a de entretenimento, mas cujas intenções verdadeiras perpassam a subordinação dos sujeitos às ideologias, especialmente, agindo em função da satisfação dos mercados.

Esse contrabando ideológico imposto pela televisão procura incutir nas pessoas uma série de valores como se fossem positivos, quando, ao contrário, em sua maior parte negativos, ou minimamente inócuos. A tentativa de imposição de valores leva os sujeitos, e principalmente as crianças, à absorção de valores sem a devida crítica, limitando sua autonomia. Em relação aos jovens, pode levar a assumirem atitudes estereotipadas para suas relações e formação de conceitos, antes mesmo de tê-las vivenciado ou raciocinado, seguindo o apresentado na TV. Com base nesses pressupostos, um dos objetivos da educação deveria ser formar os espectadores para assistirem à televisão; assim, não estariam tão sujeitos à subordinação ideológica.

A necessidade de educação para as mídias vem corroborada pela intensidade com que elas se fazem presentes na vida do homem contemporâneo. A educação, então, precisaria ser adequada à apropriação crítica desses meios. Como disse $V$ : "eu critico muito e sempre falo com minha família, a TV vende muito, tem que ter tal carro, tem que ter isto e aquilo e não é por aí. Cresce o padrão de beleza e o consumismo de lojas, roupas, academias. O que a TV quer nos passar é o consumismo."

Meira (2003) alerta para a necessidade de uma "educação do olhar", na qual é necessário desenvolver olhares que perfurem as redes imaginárias para apreender a paisagem dos acontecimentos virtuais e reais e para fazer os discernimentos éticos, estéticos e políticos que essa apreensão demanda. Essa educação do olhar poderia ser transposta à televisão e aos demais meios que se utilizam das imagens, como a publicidade, a informática e a própria arte, pois, como afirma Gomes (2002, p. 34), “[...] é praticamente impossível pensarmos o ensino das artes, e mesmo a própria Arte, fora do contexto eletrônico e midiático, onipresente na vida cotidiana da contemporaneidade". A autora infere que é através das imagens veiculadas pela televisão, que se criam e se reproduzem imaginários. A televisão seria, então, uma máquina semiótica, a maior produtora de signos contemporâneos.

O problema dessa interferência da televisão na construção do imaginário das pessoas é que o faz com base nos estereótipos, que, como já foi dito, são uma alternativa fácil para se transmitir uma determinada mensagem. Essa visão estereotipada muitas vezes é assumida pelos professores em suas relações pedagógicas, em busca de garantias de aprovação e entendimento de suas proposições pelos alunos, o que resulta em trabalhos mecânicos, sem grandes reptos. O grande desafio dos educadores em face do poder inegável da televisão continua sendo o fato de ela ainda se mostrar como uma esfinge diante de nossos olhos, suscitando uma infinidade de questões.

\section{Indústria cultural e comunicação de massa}

Questionamentos não faltam no âmbito da televisão e da educação visto que, freqüentemente nos perguntamos como foi que ela se transformou num espaço de construção/reprodução de modelos estéticos para a massa. É essa reflexão que emerge no mesmo instante em que percebemos o significativo impacto que os textos veiculados por esse meio tem junto ao processo de formação dos nossos alunos. Gradualmente, através da experiência e, mais tarde, ressignificando cada entrevista colhida, descobrimos que a matriz desta investigação está além das relações escola-televisão; ela recai no tempo-espaço das pessoas permanentemente sustentadas por uma multiplicidade de processos comunicativos, diálogos de diferentes naturezas, que garantem a compreensão e a manutenção da vida cotidiana, mas também constroem o tecido social, consolidando modelos de comportamento, valores, crenças, ideais.

Correa (2004), faz uma interessante contribuição nesse sentido. Para ele, no mundo antigo ou no mundo moderno, as relações entre sujeitos e sociedade sempre aconteceram através da linguagem. Ela é a forma de organizar e compreender o mundo que nos rodeia. Entretanto, essas idéias de mundo, traduzidas em linguagem, constituem-se a partir da forma de vida das pessoas e dos grupos aos quais estão ligadas, ou seja, a partir de suas práticas cotidianas, reforçando a condição de ser humano comunicador. Através da comunicação, é possível estabelecer elos com manifestações socioculturais distantes no tempo e no espaço, certificando-nos do conhecimento de mundo, e a ampliação do saber que daí decorre permite-nos compreender melhor o presente em nossos papéis como sujeitos históricos.

É neste aspecto que se encerra o valor da linguagem: comunicar-nos é um modo específico de estar inseridos no social, de entender as idéias de mundo de cada um e as formas como elas são mediadas, assim como os sentidos que socialmente essas for- 
mas possibilitam produzir. Barthes (1977) tem uma perspectiva social da linguagem e vê nela a expressão das relações sociais às quais estamos submetidos. Os signos dos quais a linguagem se apropria para organizar seus discursos são instrumentos de comunicação e tornam possível estabelecer um consenso acerca das idéias de mundo dos diferentes seres envolvidos nesse ambiente e, conseqüentemente, reproduzir ou questionar a ordem social e o modo como seu cotidiano está organizado. Desse modo, o discurso pode ser o lugar de exclusão ou encerramento dos sujeitos sociais, dependendo da forma que os poderes tomam para se interdizerem ou se excluírem. Em outras palavras, o poder habita a linguagem, através da língua, como instituição social que se reproduz transocialmente.

Acontece que essa infinidade de relações possíveis entre o mundo da vida, a linguagem, o sentido, a mediação e o reconhecimento do sentido, tornou-se alvo de um processo generalizado, onde "a construção do imaginário, a formulação de normas e a consolidação de visões de mundo, dependem cada vez mais da presença dos órgãos de comunicação" (CORREA, 2004, p.9). Na era do capitalismo e da organização dos mercados de consumo, os meios multiplicaram-se como os principais canais de produção e distribuição de bens culturais, dominando os espaços de troca da esfera pública e influenciando a constituição do pensamento dos sujeitos sociais.

Assim, se, por um lado, a linguagem e as formas por meio das quais ela se manifesta (formas mediadas) refletem as idéias de determinados sujeitos ou grupos sobre a realidade, a consciência que essas pessoas possuem de si, do outro e sobre o ambiente em que vive, por outro, Correa (2004) lembra que essa mediação é feita, geralmente, pelos mass media, que, por sua vez, privilegiam o consumo em detrimento da reflexão. O espaço público não é apenas mediado, mas é, também, e principalmente, mediatizado.

Mesmo que tenhamos percebido apenas recentemente o impacto provocado pelas diferentes possibilidades de comunicação social - as primeiras pesquisas brasileiras mais significativas datam da década de 1970 -, foi ainda no século XVIII, com a Revolução Industrial, a institucionalização da escola e a chegada das técnicas de reprodução, que registramos uma disseminação continuada de mensagens similares para parcelas percentualmente significativas da população, consolidando um conjunto extraordinário de circunstâncias sociopolíticas e econômicas que estabeleceram um padrão adotado pela sociedade (Defleur, Ball-Rokeach, 1989), e revelando sérias implicações, ligadas, sobretudo, aos modos de seleção e de processamento das informações, fatos e idéias transmitidas por esses meios. Estamos falando do surgimento da indústria cultural, um processo em que os veículos de comunicação fazem um papel de mediação entre a realidade e a comuni- dade de espectadores/leitores, retransmitindo, cotidianamente, uma construção do real, isto é, uma seleção de fatos retirados da cena real, decodificando-os e estruturando-os, formando mensagens e programas, que serão difundidos de modo a refletir uma ideologia, um padrão estético e as intenções que esses meios (ou seus controladores) lhes atribuem.

Comunicação de Massa é um processo industrializado de produção e distribuição oportuna de mensagens culturais em códigos de acesso e domínio coletivo, por meio dos veículos mecânicos (eletro/eletrônicos) ao vasto público que constitui a massa social, visando educá-la, informá-la, entretê-la ou persuadi-la (Beltrão, Quirino, 1986, p.57).

Com um fluxo atroz, a comunicação de massa acaba fornecendo uma série de elementos simbólicos, que levam os grupos sociais imbricados no ambiente mediatizado e alcançados por seus textos a constituírem uma representação peculiar de realidade, a consolidarem certa identidade social e, muitas vezes, baseados nisso, a confundirem cultura com diversão, misturando o genuíno com o forjado até torná-los indistinguíveis. E envolvidas nesse processo espetacular, as pessoas não têm tempo nem instrumentos capazes de lhes permitir a crítica do que consomem, já que os produtos paralisam as faculdades pela sua própria constituição, de modo a vetar a atividade mental do espectador.

Considerando esse contexto é que podemos trazer à baila algumas reflexões de Roland Barthes (1984), que visualiza o discurso como um jogo dialético baseado na mobilidade dos signos, os quais, gradualmente, vão tecendo diferentes textos. É nesses textos, especialmente aqueles postos em circulação pela mídia, que podemos perceber a emergência dos já mencionados estereótipos. Segundo o autor mencionado, os estereótipos são constituídos por uma necrose da linguagem, disfarçados de naturais, e, pela freqüência com que aparecem nos discursos, assemelham-se a uma idéia próxima da verdade, mas que pode ser apenas uma perspectiva deformada e grave. O estereótipo, então, é o resultado da imposição de determinada ideologia, que cerca e nega a multiplicidade do signo, caracterizando-se pela palavra repetida e cristalizando certo sentido como único. Assim, o autor acredita que a mídia é a grande responsável por naturalizar e eternizar essa forma de fala.

Partindo desse pressuposto é que colhemos no texto de nossas entrevistadas uma série de estereótipos, detectados pela freqüência e espontaneidade com que aparecem no texto mediatizado pelos meios de comunicação, em especial, pela televisão. Talvez o mais difundido meio de massa da contemporaneidade venha marcando o mundo comunicacional 
como espaço de negociação de sentidos, de circulação de informações e de observação do fluxo da vida cotidiana.

Embora se trate de uma investigação de cunho fenomenológico, não podemos deixar de mencionar os teóricos da Escola de Frankfurt, porque o sentido de massa foi cunhado por Adorno e Horkheimer ao se referirem à obediência inconsciente ao consumo, permitindo o surgimento da industria da cultura, como a novela da televisão e o cinema. O ideário da fenomenologia corresponde ao paradigma existencial humanista, mas o humanismo materialista da sociedade atual possui estreita relação com a comunicação de massas. A evidência das constatações de Adorno e Horkheimer (1969) sobre os produtos da indústria cultural e as reflexões de Barthes (1984) sobre os estereótipos, se reforçam significativamente nas constatações (empíricas) das alunas entrevistadas. E, por exemplo, conta que, para ela, a TV brasileira deixa o pensamento das pessoas "estagnado", não possibilitando que elas "evoluam", cresçam: "o pobre está sempre pobre". A TV produz estereótipos para "alienar" e "roubar o dinheiro do povo", e as bundas e a música melosa que costumam aparecer na programação diária servem para "iludir e alimentar".

Soma-se a essas observações a postura "crítica" que muitos dos alunos entrevistados afirmam assumir diante da programação: $N$. também se considera bastante crítica quanto à televisão: se o programa é bom, se diverte, envolve-se com o que está assistindo, contudo, se é ruim, critica. Entretanto, mesmo diante de uma observação tão otimista como parecem as anteriormente citadas, outros aspectos emergentes ao longo das conversas empreendidas com o grupo investigado, trazem novas preocupações e aumentam a inquietação mencionada pelos autores da escola frankfurtiana. É simples falar em postura "crítica", em "bons e maus programas", mas existe por parte dos telespectadores/consumidores uma real bagagem de conhecimento que viabilize um julgamento dessa natureza? Baseado em que pressupostos esses leitores televisivos optam por um ou outro programa, pelo bom ou pelo mal? Que escola e em que momento aprenderam a gramática audiovisual para realizar uma leitura eficiente deste texto?

A televisão, como um meio eletrônico, ou melhor, o texto televisivo, estrutura-se como uma teia de imagens, sons, palavras, combinadas, a partir de uma gramática particular de linguagem, cuja organização e aspectos formais da palavra escrita também determinam a intencionalidade de seu autor. Para Mello (1988), sua leitura exige do leitor uma agilidade perceptiva e uma contínua prontidão decodificadora, pois é instantânea e determinada pelo ritmo de emissão. Para tanto, ele deverá dominar previamente alguns conceitos sobre os elementos que a compõem, e as diferentes manifestações das saliências textuais e de sua organização discursiva. Além disso, também deverá carregar certa bagagem cultural que lhe permitira inferir sentidos na mensagem decodificada.

Essa segunda reflexão, acerca das inquietações provocadas pela influência dos meios de massa e, principalmente, da televisão, ressurge nas afirmações antes mencionadas de $E$. e $N$, e ganha um novo olhar centrado no depoimento de $K$. Esta última entrevistada, também afirma adotar uma postura "crítica" diante da programação televisiva, ela conta como assiste ao seu programa favorito: $O$ Ratinho (SBT). Para ela, o apresentador tem uma atitude educativa e instrutiva junto à audiência, pois muitas vezes "avisa que as cenas que ele verá a seguir são fortes e, por isso, se quiser, pode desligar a TV". K. acredita que por esse motivo, o fato de o apresentador mandar desligar o televisor caso o público não queira assistir ao que será veiculado naquele momento, denota um desinteresse do programa pelo Ibope e uma preocupação em alertar a audiência. Para a entrevistada, muitas pessoas não sabem distinguir o que é bom do que é ruim e precisam de um alerta da emissora ou do apresentador.

A leitura que $K$. talvez não tenha é que, partindo das premissas levantadas por pensadores da comunicação, esse tipo de atitude funciona como um apelo, tendo em vista que o material oferecido posteriormente traz como âncora o sensacional e o espetacular, apelos responsáveis pelos grandes índices de audiência na televisão, promovidos por programas como o citado pela entrevistada. O ideal, do ponto de vista do sistema, é o conteúdo que "[...] parece mais capaz de atrair a atenção da audiência é o espetacular (...). Visto que a meta importante do sistema de veiculação é o lucro econômico (...) é funcional na acepção de que - apesar de poder ser de mau gosto - aumenta o tamanho da audiência [...] (DeFleur, Ball-Rokeach, 1989, p.155).

$\mathrm{O}$ fato é que a presença generalizada da mídia eletrônica e seu poder de lidar com a ficção e o real, o verdadeiro e o falso no contexto de tecnologias, acessíveis hoje por todo o mundo, nos tornam personagens de uma civilização visual e, por isso, estamos sujeitos ao bombardeio contínuo de informações visuais, emitidas principalmente pelos meios de comunicação. A televisão, por exemplo, cercanos no espaço público e no espaço privado de tal maneira que já estamos acostumados a ela e à constância com que surge.

A televisão é um espaço fundamental de análise se observarmos que pode ser o espaço por meio do qual diferentes gerações acessam textos dos quais podem divergir ou com eles concordar. A leitura que cada agente social vai assumir diante do difundido e dos diálogos construídos ou a partir deles, depende, inicialmente, das negociações individuais que esses sujeitos estão aptos a fazer. "A televisão até mesmo pela sua difusão - acaba sendo atualmente o espaço privilegiado onde está presente a 
diversidade cultural, as divergências e as oposições. Por isso se diz que são "espaço de conflito", pois "o gosto" que alcança a hegemonia é por ele referendado."(MACHADO, 2002, p.10).

Referendando as escolhas que o telespectador tem de fazer diante dos textos propagados pela TV, merece destaque o depoimento de uma das alunas entrevistadas. N. utiliza a palavra "contraditório" para referendar o espaço de conflito caracterizado pelo discurso televisivo: "A televisão é um veículo contraditório, porque, ao mesmo tempo em que apresenta campanhas contra drogas, o cigarro, por exemplo, mostra os ídolos fumando, levando o jovem que vê seu ídolo fumando, seguir seu exemplo."

Outro aspecto da fala de Machado (2002), empiricamente pontuado por uma aluna, é a batalha cultural que flui na dinâmica de sua construção textual. Para $J$. a televisão não apresenta uma programação importante para ser vista, nem permite a expressão das diferentes idéias; ela trabalha apenas em torno da questão financeira, o que justificaria o fato de a programação estar voltada para o consumo, como modo de padronização.

Chauí (1997) afirma que, visto do aspecto da manutenção social, pode parecer hoje que os conflitos enfrentados no bojo da sociedade são culturais, não mais políticos. É notória a pluralidade de culturas no mundo moderno, mas também dos desníveis de expressão das mesmas. $A$. lembra, ainda, que esses conflitos dependem da diversidade cultural do público a quem a televisão se dirige, mas à qualidade da programação que produz. Para ela faltam programas educativos, filmes, cultura brasileira, enfim. A televisão poderia ser uma alternativa cultural para pessoas que moram em cidades do interior, como ela, que não tem acesso a outras programações, porém, isso não ocorre pela falta de qualidade da programação.

Nesse sentido $I$. afirma que o que move a programação da TV é a busca pela audiência, associada ao desrespeito e às conseqüências dessa postura diante do público. Tal característica pode ser evidenciada observando o destaque dado para programas sensacionalistas, que mostram "dor, sofrimento e pobreza". I. diz que, aparentemente, isso funciona como uma espécie de consolo para quem assiste, ou seja, perceber que os problemas não existem só na vida de uma pessoa, mas na vida dos vizinhos e na TV. Entretanto, a entrevistada observa que esses programas são veiculados para desviar a atenção do telespectador da realidade, estimulando-o ao conformismo.

Os meios fazem um papel de mediação entre a realidade e a comunidade de espectadores/leitores, retransmitindo, cotidianamente, uma construção do real, isto é, os meios (ou seus controladores) selecionam apenas alguns dos muitos fatos e situações decorrentes na cena real, decodificam-nos e estruturam-nos (estabelecendo relações de seu inte- resse), formando mensagens e programas que serão difundidos, refletindo uma ideologia e um padrão estético. $W$. afirma que a TV esconde a realidade, os problemas políticos e aliena a população. Para ela, seu papel é discriminador e anestésico; por isso, se tivesse filhos, não permitiria que eles assistissem à televisão. Aliás, a observação de $W$. representa a opinião de muitas das alunas entrevistadas. Entretanto, apesar da preocupação explícita, é possível identificar poucas alternativas ou mecanismos utilizados pelas entrevistadas para evitar o contato de seus filhos, irmãos, sobrinhos, com a programação que criticam. A principal justificativa sobre esses aspectos centra-se na dominação dos canais de TV aberta e no difícil acesso, devido ao alto custo, aos canais de TV a cabo, onde, segundo elas, estariam os melhores programas.

Em outras palavras, a televisão, como meio através do qual circulam mensagens de diferentes perspectivas a cerca do mundo da vida - mesmo que citado genericamente -, é um espaço onde emergem as semelhanças, contradições, coerências e incoerências da sociedade. Entretanto, ao que parece, é um espaço que hoje, em detrimento do desassossego, busca muito mais estabelecer e referendar valores do que questionar. Prova disso está no pensamento expresso por nossas alunas, através das entrevistas e da consolidação dos estereótipos vendidos pela televisão, em especial pelas narrativas, como a telenovela.

Esse formato, do gênero entretenimento, é um dos mais recorrentes entre as entrevistadas. Se observarmos com cuidado os modelos citados pelo grupo como exemplo de estereótipo, de fala repetida e distorcida da realidade, como quer Barthes (1984), mas também naturalizada e banalizada pela freqüência com que aparece na televisão, poderemos perceber que correspondem às personagens apresentadas ao longo da trama.

No entanto, o reconhecimento e a descrição dos modelos estéticos apontam não apenas para as referências de comportamento social que refletem num dado tempo-espaço, mas também para a recorrência com que o público assiste a eles para poder identificá-los como tais. As personagens e plasticidade construídas para elas pelos atores, só se consolidam a partir da freqüência com que são apresentadas. Portanto, além de contribuir para a formação dos estereótipos, o texto televisivo também contribui para a formação de outros "gestos de leitura" (CHARTIER, 2000) da audiência e das relações sociais que estabelece ou modifica através dele. Em consonância com este aspecto, trazemos a fala de $A$, para quem, o exemplo de leitura eficiente repousa sobre aquela realizada pela figura materna, com a qual concorda. Para sua mãe, a novela representa um malefício, porque gera uma expectativa diária nas pessoas, que não perdem o capítulo, largando qualquer atividade durante a transmissão. Ainda sobre essa pers- 
pectiva, $N$, outra entrevistada, conta que sua relação com a televisão é conflituosa, não apenas pelo conteúdo e forma com o que se apresenta, mas pela sua presença física no cotidiano da família. Para ela, a TV interrompe o diálogo na casa, o que a deixa triste, pois, no horário da novela, ninguém pode "dar um pio", o que a impede de conversar, de dividir o que se passou durante o dia. Nesse contexto, a televisão ganha o status de preciosidade na casa em detrimento das pessoas. $N$. acredita que essa falta de diálogo pode interferir nas atitudes dos jovens, levando-os, por exemplo a suprir a ausência do diálogo pelas drogas.

\section{Considerações finais}

Talvez seja necessário lembrar que o princípio da comunicação, em qualquer modalidade, pressupõe interlocução, ou seja, diferentes sujeitos imbricados num processo de interação e intercâmbio de signos através dos quais compartilham experiências cotidianas. Entretanto, uma vez que essa interação não se efetiva de modo eficaz com o texto televisivo, em razão da natureza técnica do meio, essa interlocução acaba projetada para fora dele, na rua, no palco, na cena social. São múltiplos os caminhos em que o texto da TV salta para fora dela. Mas, para que essa interlocução seja significativa, é preciso romper com a muralha de estereótipos estabelecidos. É preciso que esses outros espaços, aqueles "fora da televisão" e do processo desencadeado pela indústria cultural junto aos meios de comunicação, estejam preparados para construir uma bagagem sólida de conhecimentos que permitam a resistência à "pintura fácil" da realidade, aquela das folhas com silhuetas para colorir. Que a educação seja o pincel e a tesoura que possibilite rasgar essas folhas e montar um novo mosaico, do qual tenhamos consciência de ter construído.

Nossas questões iniciais foram respondidas amplamente pelas entrevistadas ao mostrarem com clareza os estereótipos humanos construídos/reproduzidos pela mídia televisiva, assim como quais eram apresentados a partir dos seus olhares. Novos questionamentos surgiram durante as entrevistas na fase de compreensão e ainda hoje. Sabemos que, após a conclusão deste estudo, continuarão se mostrando diversas fases do fenômeno, que, provavelmente, oportunizarão a sua continuidade em outras realidades educativas ou comunicacionais. mFamecos

\section{REFERÊNCIAS}

ADORNO, T.; HORKHEIMER, M. Teoria da cultura de massa. S. Paulo: Paz e terra, 1969.

ALVES, G. A. O quotidiano visto através da TV. In: MESQUITA, Z.; BRANDÃO, C.R. (Org.) Territórios do cotidiano: uma introdução a novos olhares e experiências. Porto Alegre/
Santa Cruz do Sul: Ufrgs/Unisc, 1995. p. 191-206.

BARTHES, R. Aula. São Paulo: Cutrix, 1977.

. O rumor da língua. São Paulo: Brasiliense, 1984.

BELTRÃO, L.; QUIRINO, N. de O. Subsídios para uma teoria da comunicação de massa. 2.ed. São Paulo: Summus, 1986.

CHARTIER, R. A aventura do livro: do leitor ao navegador. São Paulo: UNESP, 2000.

CHAUÍ, M. H. Cultura e democracia: o discurso competente e outras falas. São Paulo: Cortez, 1997.

CORREA, J. C. Comunicação e cidadania: os media e a fragmentação do espaço público nas sociedades pluralistas. Lisboa: Livros Horizonte, 2004.

DEFLEUR, M.; BALL-ROKEACH, S. Teorias da comunicação de massa. Rio de Janeiro: Jorge Zahar, 1989.

FERRÉS, J. Televisão e educação. Porto Alegre: Artes Médicas, 1996.

GOMES, P. B. A formação de visualidade, imaginário e estereótipos. Revista da Fundarte. Montenegro, ano II, volume II, número 04, jul.-dez. 2002. p.32-40.

MACHADO, E. S. A televisão como ampliação da esfera do ser e do gosto. In: INTERCOM, CONGRESSO BRASILEIRO DE CIÊNCIAS DA COMUNICAÇÃO, 25, 2002, Salvador. Anais... Salvador: Universidade Federal da Bahia, 2002.

MEIRA, M. Filosofia da criação: reflexos sobre o sentido do sensível. Porto Alegre: Mediação, 2003.

MÈLICH, J-C. Del extraño al cómplice: la educación en la vida cotidiana. Barcelona: Anthropos, 1994.

MELLO. J. M. de. Comunicação: teoria da comunicação: paradigmas latinoamericanos. Petrópolis: Vozes, 1988.

ORMEZZANO, G.; TORRES, M.C. Máscaras e melodias: duas visões em arte e educação. 2.ed. São Miguel do Oeste: Arco Íris, 2003. 